\title{
The Institutional Regulatory Environment of the Digital Ecosystem: Theoretical Approach and Russian Experience
}

\author{
Natalya Masyuk $^{1 *}$, Marina Bushueva ${ }^{2}$, Zinaida Bragina $^{3}$ \\ ${ }^{1}$ Vladivostok State University of Economics and Service, Gogolya st. 41, 690014 Vladivostok, Russia \\ ${ }^{2}$ Russian University of Economics by GV Plekhanov (Ivanovo Branch), Ivanovo, Russia, \\ ${ }^{3}$ Kostroma State University, Ulitsa Dzerzhinskogo 17, 156005 Kostroma, Russia
}

\begin{abstract}
Digitalization is an integral part of global change in the world economy. The successful creation and functioning of a digital economy are possible only in an adequate digital ecosystem. The main criterion for the formation of a digital ecosystem is the maturity and stability of its institutional environment, including the totality of new institutions. The creation of digital institutions is a new phenomenon of institutionalization and accompanies the introduction of digital technologies in the digital ecosystem. The article defines the concept of institutionalization in connection with the analysis of the economic interests of business entities operating in the regions of Russia. The definition of digital institutions as new social institutions in the digital age is formulated. The structure and basic elements of the institutional regulatory environment of the digital ecosystem that is necessary for regulating digital transformations in the digital ecosystem are determined.

Keywords: institutionalization, digital economy, digitalization, digital ecosystem, digital transformation, digital institutions, institutional regulatory environment.
\end{abstract}

\section{Introduction}

Institutionalization is the process of determining and consolidating social norms, rules, statutes, and roles, turning them into a system that can satisfy certain social and economic needs, which is largely determined by global changes in the global economy [1]. Globalization is accompanied by a deep institutional transformation that characterizes the current stage of development of the digital economy [2,3].

Currently, the categorical apparatus of a new scientific direction - digital economy - is actively discussed in the scientific and methodological literature [4]. In the "Strategy for the Development of the Information Society of the Russian Federation for 2017-2030", the

${ }^{*}$ Corresponding author: masyukn@gmail.com 
digital economy is understood as follows: "The digital economy is an economic activity in which the key factor in production is digital data, the processing of large volumes and the use of analysis results which are compared with traditional forms of management can significantly increase the efficiency of various types of production, technology, equipment, storage, sale, delivery of goods and services "[5]. The above definition is quite general, not reflecting the semantic meaning of the term; therefore, it is necessary to reveal the main features of the digital economy. These include:

- the creation of cyber-physical systems in which a person and a machine represent a single, harmoniously working organism

- the use of intelligent platforms in all areas of socio-economic activity;

- the introduction of the Internet of people, the Internet of things, the Internet of services (along with the already well-developed Internet of ideas) [6];

- application of Big Data technologies (processing of "big data");

- the use of modern information technologies, such as block-chain, ensuring transparency of transmission, reliability of data storage; nadge-technologies that promote the marketing of products (goods and services), etc. [7,8].

These signs do not have clearly defined areas of action. Their effects intersect, creating a positive synergistic interaction effect. For example, the cyber-physical system of the regional economy is based on the introduction of digital platforms using Big Data, block-chain, and nadge-technologies. In this system, based on the Internet of people, professional expert communities are formed, and Internet services allow enterprises in the region and its population to improve the quality of the services provided (at work, in private life). The Internet of things "aligns" the role of man and machine in the organization of production and business activities.

The relevance of the study is determined by the fact that the institutionalization of digital transformations for modern Russia is a special economic resource that allows you to adapt the institutional foundations of economic growth to Russian conditions at the present stage of development. With the development of digitalization, the institutional economy receives a new version of life - a new field of problems generated by a change in the medium of the economic entity, its reflection, and measurement, represented by indicators, coefficients, indices, etc. An innovative ecosystem of the digital economy is being formed [4, 9, 10, 11].

In the Strategy for the Development of the Information Society in the Russian Federation for 2017-2030. The ecosystem of the digital economy is defined as "a partnership of organizations that ensures the constant interaction of their technological platforms, applied Internet services, analytical systems, information systems of state authorities of the Russian Federation, organizations and citizens" [5]. However, there are other definitions of a digital ecosystem, for example: a "digital ecosystem" is a multi-structural relationship between the main actors of the digitalization of the economy (population, state, business structures) and the basic conditions for their functioning [12].

Growth points of the digital economy of Russia can be both sectors of the national economy and the subjects of the Federation [13]. Currently, the government's digitalization program for the Russian economy focuses on large industry holdings and state corporations. Indeed, within these associations, which have sufficient resources (financial, labor, intellectual), already have a high starting position, and, most importantly, relying on concentrated management, the solution to the problems of digitalization of the economy seems to be the most promising [14]. Currently, the introduction of elements of the digital economy, primarily digital platforms, is limited mainly by the development of social and communication services (Internet, mobile communications, utility bills, banking, online ticketing, etc.) [15]. Often the introduction of digital tools is accompanied by a conflict between the old, familiar methods of doing business and innovative ones, the introduction of 
innovations must be carried out consistently, resolving contradictions using local compromises [16].

\section{Method and methodology}

The theoretical and methodological basis of this study is based on a set of fundamental premises of the classical and modern economic theory about the objective conditionality of the development process, its sources, forms, orientation and limitations, based on the provisions of classical economic theory, the provisions of institutional theory using the methodological tools of genesis, evolution and development socio-economic systems [17, $18,19]$. This study was conducted on the basis of a system-institutional approach, which is a synergistic combination of the "concept of a system economy" and institutional theory. The concept of a systemic economy focuses on "complex" socio-economic formations in which certain combinations of internal forces and external conditions provide relative stability in time and space. At the same time, the methodology of a systemic economy expands the boundaries of systemic vision by introducing into the scope of interdisciplinary consideration the fields of scientific knowledge related to the areas of knowledge bordering on the economy in a given space: psychology, mathematics, sociology, computer science, regional studies, etc. Under the system (in the framework of the theory of economic systems) we understand the relatively isolated and relatively stable in space and time part of the world (considered as a system-containing space in), characterized by external integrity and internal manifold [20]. At the same time, the continuous process of the network economy should be taken into account [21]. Institutional economics uses the concept of "institute," the focus is currently on social institutions. Social institutions are value-normative complexes (values, rules, norms, attitudes, patterns, standards of behavior in certain situations), as well as bodies and organizations that ensure their implementation and approval in society. The signs of a social institution include: a set of institutions, social groups, the purpose of which is to satisfy one or another of the needs of society; system of cultural patterns, norms, values, symbols; a system of behavior in accordance with these standards and patterns; material and human resources necessary for solving problems; socially recognized mission, goal, ideology. All these signs will be used by us in the future to define the concept of "digital institutions".

\section{Results}

As a result of the study, the authors propose to introduce the concept of "digital institute" and "institutional regulatory environment of the digital ecosystem" into business circulation. According to the definition of a social institution given above, it can be argued that digital institutions are a form of social institutions. Moreover, by a digital institution, we mean the regulatory tools of the digital ecosystem, i.e. a set of various tools - electronic products and services that contribute to the development and implementation of digital technologies. According to the authors, the digital ecosystem for successful development requires the creation of certain conditions or a special institutional environment that will regulate digital transformation.

Based on this postulate, as well as on the basis of the above definition of "digital institution", a structural diagram of the institutional (regulatory) environment of the digital ecosystem was developed (Fig. 1) and its definition is given. It is proposed to understand the institutional regulatory environment as a system of electronic products and services that accompany the creation and development of digital institutions, as well as regulatory decision-making procedures and entities involved in regulatory decisions. 
Digital institutions, in turn, consist of hard regulation tools (laws, other regulations, etc.), soft regulation tools (recommendations, clarifications, instructions, standards of selfregulatory organizations, etc.), as well as "regulatory sandboxes" under which special legal regimes are understood. Regulatory sandboxes are a separate type of special regime, which is temporarily facilitated conditions for the implementation of innovative projects. Their main advantage is a reduction in regulatory pressure on innovative business with minimal risks due to the limitation of the scope of experimental activity.

\section{Discussion}

In the process of digitalization, the most important aspect is its legislative support. In Russia, there are still many weaknesses in this direction. But in fairness, it should be noted that in solving this issue the Russian authorities are not marking time. So, the first package of amendments is already being prepared for introduction to the State Duma, regulating issues of personal data circulation, protection, and ease of use of digital signatures, the introduction of electronic workbooks, etc. [22]. It is assumed that in 2021 universities in Russia will start issuing new-type diplomas that are protected by the block-chain, etc. Despite the technological and financial difficulties, the penetration of digital technologies into innovative businesses cannot be stopped.

In Russia, among the areas whose representatives have already relied on digital transformation, are transport and logistics. In these industries, freight and passenger autopilot vehicles are already being tested, based on the Internet of things, big data, neural networks, and other technologies. Intelligent transport systems are also actively developing, including at the initiative of the state. Among the examples of the latter are the Plato system and automated weight and dimensional control systems (ASVGK), the number of which is growing year by year. 

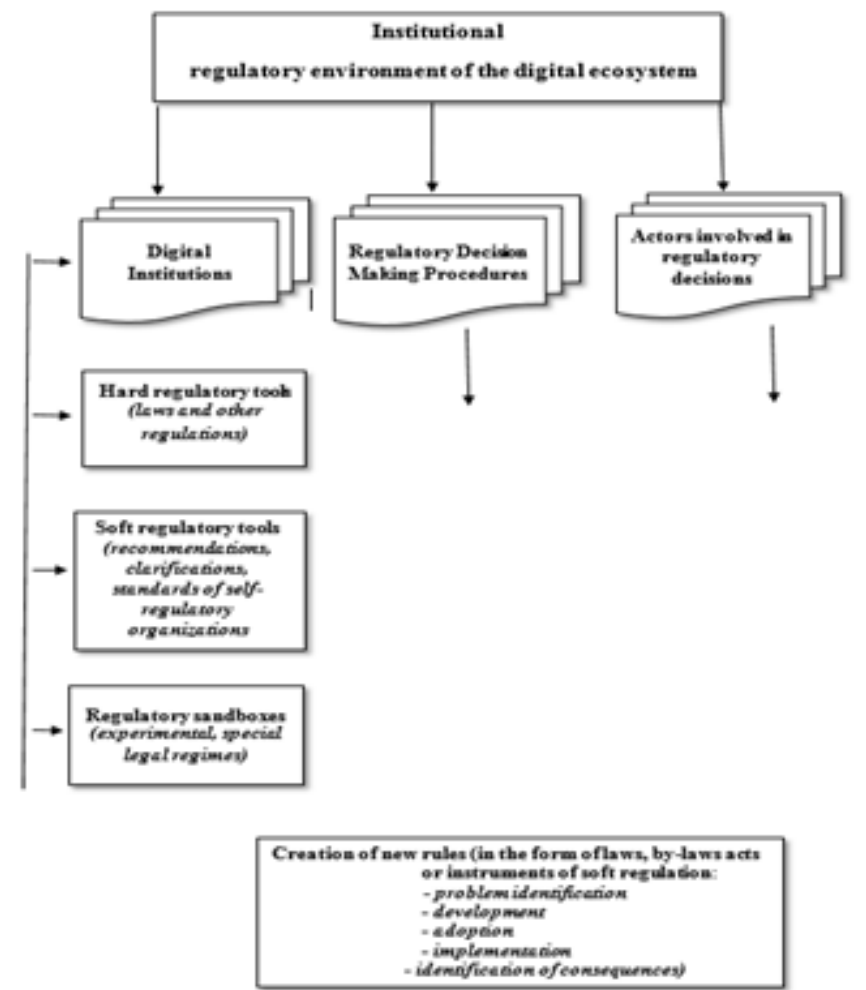

Fig. 1. Institutional regulatory environment of the digital ecosystem

Source: Own processing.

Car sharing also demonstrates the effectiveness of the synergistic approach. Participants in this market represent one of the most promising trends for the industry - mobility as a service (MaaS). In the future, this approach can completely change the urban transport environment. Car sharing companies are constantly introducing new tools - from chatbots to recognizing a user by face and voice. This facilitates interaction with customers and ensures the safety of the fleet.

Logistics also goes to a new level. Fleet and cargo control services are already quite routine. New possibilities appear: for example, special sensors monitor the position and movement of cargo in space, including the tilt axis, the temperature regime of transportation (for perishable goods or goods with special transport conditions), monitor the condition of the driver by eye movement, and so on.

One of the most revolutionary trends for Russian logistics in the future should be the development of platform solutions for the search and selection of freight carriers (an analog of Uber for freight transport), the organization of multimodal transportation [6]. Similar platforms are based on cloud technologies, Big Data and other tools. It is thanks to the synergy that, according to experts, they are able to completely transform the market, as has already happened in the field of taxi transportation, which has radically changed due to the so-called Uberization. Obviously, similar changes in the freight market are a matter of time. 


\section{Conclusion}

The development of the digital economy is currently one of the most significant global trends, the consequences of which are felt in various spheres of life. Under these conditions, in many countries, strategies and plans for the formation of a digital economy have been developed and are being implemented. Digital institutions are emerging as a new kind of social institutions in society. In Russia in 2017 , documents were also adopted that defined the prospects for this area, including the Strategy for the Development of the Information Society and the Digital Economy in the Russian Federation Program. It is obvious that digitalization in the near future will be the most important factor in the development of each region and the country as a whole. No wonder the digital economy is often called the chance for a breakthrough in many areas: in the economy, industry, infrastructure, the quality of life of a particular person, etc. Moreover, the regulatory institutional environment in which digital transformations take place will be of decisive importance.

\section{References}

1. N. Baranov, Institutionalization in Russia: features of national model. Political Expertise: PolitEx, 3(4), 69-87 (2007)

2. N.S. Revenko, The US digital economy in the era of information globalization: current trends. The USA and Canada: Economics, Politics, Culture, 8(572), 78-100 (2017)

3. N.N. Masyuk, M.A. Bushueva, L.K. Vasyukova, A.E. Kiryanov, Platforms of digital experience and digital transformation in an innovative economy. Proceedings of the III International Scientific and Practical Conference "Resonances Science" (2018)

4. E. Avramakis, J. Anchen, A. Raverkar, Digital ecosystems: extending the boundaries of value creation in insurance. Swiss Re Institute [online], Available at: https://www.swissre.com/institute/research/topics-and-risk-dialogues/digital-andtechnology/Digital-ecosystems.html (2019)

5. The Strategy for the Information Society Development in the Russian Federation for 2017-2030, Presidential Decree \# 203 of 9 May 2017 was approved

6. V. Mesropyan, Digital platforms - a new market power [online], Available at: https://www.econ.msu.ru/sys/raw.php?o=46781\&p=attachment (2018)

7. L.L. Avdeeva, Analysis of the prospects for the development of the digital economy in Russia and abroad. Digital Economy and "4.0 Industry ": problems and prospects: works of the Scientific and Practical Conference with International Participation, pp. 19-25 (2017)

8. N.D. Bublik, I.I. Lukina, D.V. Chuvilin, T.A. Shafikov, R.F. Janusova, Development of the digital economy in the regions of Russia: problems and opportunities (for example, the Republic of Bashkortostan). Regional Economics and Management [online], Available at: https://eee-region.ru/article/5313/(2018)

9. A. Corallo, G. Passiante, A. Prertcipe, The Digital Business Ecosystem. Edward Elgar Publishing Limited, 41-42 (2007)

10. N.V. Smorodinskaja, Network Innovative Ecosystems and Their Role in the Dynamization of Economic Growth. Innovations, 7(189), 27-33 (2014)

11. D. Jackson, What is an Innovation Ecosystem? [online], Available at: http://ercassoc.org/sites/default/files/topics/policy_studies/DJackson_Innovation $\% 20$ Ecosystem 03-15-11.pdf (2011) 
12. V.V. Stepanova, A.V. Ukhanova, A.V. Grigorishchin, D.V. Yakhyaev, Evaluating digital ecosystems in Russia's regions. Economic and Social Changes: Facts, Trends, Forecast, 12(2), 73-90 (2019)

13. O. Sukharev, Institutional Change, Efficiency and Structure of Economy. Lambert Academic Publishing (2011)

14. Methodology of development of the economy, industry and services in the conditions of digitalization / Ed. A.V. Babkin. SPb: Polytech-Press. DOI.10.18720 / IEP / 2018.6 (2018)

15. N.N. Masyuk, Z. Chen, L.K. Vasyukova, Change management and digital transformations in the era of business digitalization. In the collection: The economy of the regions of Russia: current state and forecast prospects. A collection of articles based on the materials of the All-Russian Scientific and Practical Conference of teachers, graduate students, undergraduates of the Ivanovo branch of the Russian Economic University named after G.V. Plekhanov, pp. 253-258 (2019)

16. N.N. Masyuk, M.A. Bushueva, L.K. Vasyukova, N.A. Mosolova, Innovative Managerial Decisions: Towards a Conflict-Compromise Approach. Precedings in $32^{\text {nd }}$ IBIMA Conference (2018)

17. J.A. Shumpeter, The Theory of Economic Development. Russia, Moscow: Progress, (1982)

18. J.F. Moore, The Death of Competition: Leadership and Strategy in the Age of Business Ecosystems. N.Y.: Harper Business (1997)

19. C.W. Wessner, Entrepreneurship and the Innovation Ecosystem. Policy Lessons from the United States. The Papers on Entrepreneurship, Growth and Public Policy (2004)

20. A.B. Kleiner, System economy as a platform for the development of modern economic theory. Economic Issues, 6, 7, (2013)

21. Z.V. Bragina, M.L. Irodov, A.V. Maslova, From network interactions to a network economy. Russia, Yaroslavl: MUBiNT (2016)

22. A.A. Berezutsky, Informal aspects of the institutionalization of the Russian political elite. Management consulting, 5, 171-177 (2017) 